\title{
Anthropometry and Blood Pressure Changes in a Caribbean Adolescent Population of African Ancestry. An Evaluation of Longitudinal Data Using a Multilevel Mixed Regression Approach
}

\author{
S Nichols $^{1,2}$, F Cadogan $^{2}$
}

\begin{abstract}
Objective: The aim of this study was to determine the effect of growth pattern on blood pressure changes in an adolescent population of African ancestry based on longitudinal data and to compare this with estimates derived from cross-sectional data.

Methods: Participants had measurements of weight, height, blood pressure and percentage body fat taken annually using standardized procedures. Annual blood pressure and anthropometry velocities as well as one- and three- year interval gender specific tracking coefficients were computed. We investigated whether changes in blood pressure could be explained by measures of growth using a multilevel mixed regression approach.

Results: The results showed that systolic blood pressure (SBP) increased by 1.27 and 3.09 mmHg per year among females and males, respectively. Similarly, diastolic blood pressure (DBP) increased by 1.16 and $1.92 \mathrm{mmHg}$ per year among females and males, respectively. Multilevel analyses suggested that weight, body mass index, percentage body fat and height were the strongest anthropometric determinants of blood pressure change in this population.
\end{abstract}

Keywords: Adolescence, blood pressure, longitudinal, multilevel analyses

From: ${ }^{1}$ Department of Agricultural Economics and Extension, The University of the West Indies, St Augustine and ${ }^{2}$ Tobago Hypertension Society, Trinidad and Tobago.

Correspondence: Dr S Nichols, Department of Agricultural Economics and Extension, The University of the West Indies, St Augustine, Trinidad and Tobago. E-mail: snichols@trinidad.net 
The results also suggest that there are gender differences in the relative importance of these anthropometric measures with height playing a minor role in predicting blood pressure changes among adolescent females. With the exception of DBP at 18 years among females, there were no significant differences between mean blood pressure generated from cross-sectional and longitudinal data by age in both males and females.

Conclusion: Anthropometric measures are important covariates of age-related blood pressure changes and cross-sectional data may provide a more cost-effective and useful proxy for generating age-related blood pressure estimates in this population. 


\section{INTRODUCTION}

The World Health Organization identifies high blood pressure as the leading risk factor for mortality, accounting for $13 \%$ of deaths globally (1). Over $20 \%$ of adults in the Caribbean are afflicted with hypertension and its co-morbid conditions (2-4). This increase in prevalence and levels of blood pressure are due to changes in lifestyle behaviours that have accompanied the improved economic situation in most countries of the region following the post-colonial era (5). Concomitant with these increases in the levels of adult blood pressures were increases in body weight, reduction in the levels of physical activity and consumption of diets consisting mainly of foods high in refined sugar, fats and salt $(5,6)$. Hypertension and its co-morbidities place additional burdens on the already overstressed regional health systems. Together with diabetes mellitus, they account for the bulk of visits to public health institutions regionally. They also contribute to low worker productivity which may impact on economic development in the region (5).

Increasingly, it is being recognized that risk factors for hypertension are present in early life. Prospective studies have demonstrated increases in left ventricular mass and peripheral resistance with elevated blood pressure in childhood (7-10). Moreover, blood pressure in childhood and adolescence are known to track into adulthood. In fact, the tracking coefficient for blood pressure increases with age (11-12). Childhood and adolescent blood pressure levels are strongly influenced by growth patterns, age and gender (13). Given these findings, it is necessary that blood pressure changes during these early phases of life be evaluated to determine the major drivers of the rate of blood pressure change. Most of the data on adolescent blood pressure have been generated from cross-sectional studies of adolescent populations. 
These studies report inter-individual rather than intra-individual variability in blood pressure. This begs the question as to whether estimates arising from cross-sectional data are similar to those expected from individuals followed over time. Logically, measures of blood pressure taken on an individual over any time period would be expected to be more closely correlated than blood pressure measurements of different individuals of a similar age group. This may have implications for the nature of the results generated. Moreover, adolescents of African ancestry are prone to developing higher levels of blood pressure with age (14). The aims of this study were to determine the effect of age and anthropometric changes on the rate of blood pressure change in an adolescent population of African ancestry and to compare these results with those obtained from cross-sectional data collected from the same population (15). 


\section{SUBJECTS AND METHODS}

All adolescents entering secondary school during the period September 2000 to January 31, 2001 were invited to participate in the survey. Parental consent as well as the approval of the Division of Education, Tobago House of Assembly, was obtained prior to commencement of the study. All participants were examined in school uniform. Blood pressure readings were taken on the right arm with a Baumanometer mercury sphygmomanometer (WABaum, New York) after each participant had rested in a sitting position for five to 10 minutes with the right arm resting on a table at the level of the heart. The details of the methods have been described elsewhere (15). Systolic blood pressure (SBP) was recorded at the beginning of the first Korotkoff phase and diastolic blood pressure (DBP) at the ending of the fifth Korotkoff phase. The average of two such measurements three minutes apart was used in determining the systolic and diastolic blood pressure for each participant. Height was measured to the nearest millimetre with a portable stadiometer while weight was measured to the nearest $0.1 \mathrm{~kg}$ using standard anthropometric methodology (16). All anthropometric and blood pressure measurements were taken annually during the anniversary period over a five-year period by health personnel who underwent annual retraining specifically for this survey. Body mass index (BMI) was calculated by dividing the participants' weight in kilograms by their height squared in meters. Percentage body fat (\%BF) was measured to the nearest $0.5 \%$ using a body fat analyser (Tanita, Model 351). This device is easy to use and produces good population estimates of percentage adiposity (17-18). 
Statistical analyses were conducted using STATA version 9.0. Prior to analyses, all data were checked for errors and deviations from normality. Simple descriptive analyses were used to summarize data. Unpaired $t$-tests were used to analyse gender differences among variables and to compare blood pressure and anthropometric measures by gender. Pearson blood pressure tracking correlation coefficients were computed at one- and three-year intervals. Change in blood pressure was analysed using individual growth curve modelling within a multilevel mixed regression framework. This type of modelling includes the use of random and fixed effects (20). Fixed effects are repeatable measures. In this study, they were the anthropometric covariates of the rate of blood pressure change and included height, weight, BMI and per cent body fat which were recorded annually. We also included two types of random effects - a random intercept and a random slope. The random intercepts represent adjustment to the main intercept for each individual. This is important as changes in blood pressure may be dependent on initial blood pressures level. Inclusion of random slopes results in adjustment of the slope of a given covariate for each level of the random effect. The effect of accounting for these individual variations is to produce estimates of the fixed effects (covariates) that are more reliable and accurate (21). One advantage multilevel mixed regression model has over traditional regression analyses is that it takes into consideration between-group effects and within-subject (individual) effects in variation when modelling change (21). This is important as repeated measures of blood pressure, height, weight, BMI and per cent body fat within subjects was expected to be more highly correlated than measurement between subjects. Failure to take different levels of variation into consideration can result in estimates that are biased (21). Another important aspect of multilevel mixed regression modelling is that it does not require that all individuals have the 
same number and timing of measurements. In traditional regression analyses, missing data may affect the power of the study and the resulting regression coefficients (22).

In this study, we evaluated whether changes in blood pressure could be explained by measures of growth, adiposity and age. We fitted six gender-specific models. Model 0 (the "empty" model) did not include any explanatory variables and focussed on describing only individual and population components of variance in blood pressure. In model 1, age was added as both a fixed effect and random effect (slope). In model 2, height was added to the first model. In models 3-5, either weight, height, BMI or per cent body fat was added to model 2 . The model parameters were estimated by the method of iterated generalized least squares, which under normality assumptions leads to maximum likelihood estimates (23). Tests of statistical hypotheses were carried out through the use of Wald tests (ratio of an estimated parameter to its standard error). A $p$-value of 0.05 was used as the criterion of significance for all statistical testing. Thus, repeated measures of diastolic and systolic blood pressures were regressed on anthropometric measures and age in sex-specific regression equations. In the initial analyses, age, $\mathrm{age}^{2}$, height and either weight, BMI, percentage adiposity and the relevant age-byanthropometric and body composition interaction term (ie age-by-height, age-by-weight or ageby-BMI or age-by-percentage adiposity) were considered. The age ${ }^{2}$ term was not significant and as such was excluded from further analyses. In these analyses, age was centred to 12 years while anthropometric variables were centered at their minimum value. Centering facilitates easier interpretation of the intercept (24). In the case of model 1, the level of blood pressure at age 12 years, analyses showed that age-by-height, age-by-weight or age-by-BMI or age-by-percentage adiposity interactions did not yield $p$-values less than 0.05 and these were excluded from further consideration. 


\section{RESULTS}

Table 1 shows the physiological characteristics of participants at baseline by gender. Males 14 to 17 years had significantly higher systolic blood pressure than their female counterparts. Females 13 years old had significantly higher diastolic blood pressure than their male counterparts. The converse was true at 16 years of age. Males 12 to 13 years were significantly lighter than females. However, by ages 15 to 17 years, males were significantly heavier that their female counterparts (Table 2). Males were significantly taller than their female counterparts except at age 13 years (Table 2). Females 13 and 14 years old had significantly higher BMI than their male counterparts while males had significant lower levels of body fat than females.

Table 3 shows the age and sex-specific tracking correlation coefficient for systolic and diastolic blood pressure at one and three-year intervals. There was a general increase in the one-year tracking coefficient for systolic blood pressure for both males and females. Generally, the one-year tracking coefficient for SBP tended to be higher than the three-year tracking correlation coefficient. Among females, the one-year tracking coefficient for diastolic blood pressure was significant over the ages of 12-17 years, while it was significant from 12-15 years among males.

Figure 1 shows the annual rates of changes in systolic BP, BMI, weight and height by gender. Peak velocities for SBP occurred at 12-13 years and 15-16 years among females and 13-14 years and 16-17 years among males. Among females, peak BMI and weight velocities occurred between ages 12-13 years. Among males, peak weight and height velocities occurred between 13-14 years while peak BMI velocity occurred at age 12-13 years. Figures 2 and 3 show the correlation coefficient of annual weight, height and BMI with SBP and DBP by gender, respectively. Correlation coefficient between annual weight, height, BMI and SBP showed non- 
linear characteristics with age. Among females, the highest correlation coefficient occurred at ages 11-12 years and again at ages 16-17 years. Among males, the highest correlation coefficient occurred at ages 11-12 years and again at age 17-18 years. Overall, for both SBP and DBP, correlation coefficients were higher for weight and BMI than they were for height (Figs. 2 and 3). Figure 4 shows a comparison of blood pressure changes with age from crosssectional data on adolescents of similar age group from this population and data emanating from this study. In all cases, the gradients of the slope were higher for age-related changes in blood pressure from the cross-sectional study. With the exception of DBP at 18 years among females, there were no significant differences between mean blood pressure generated from crosssectional and longitudinal data by age and gender.

Tables 4 and 5 show the results of mixed regression modelling of anthropometric and obesity indices on the rate of change of SBP and DBP, respectively. The average SBP was 104.0 and $101.4 \mathrm{mmHg}$ among 12-year old females and males, respectively. Systolic blood pressure increased by an average of $1.27 \mathrm{~mm} \mathrm{Hg}$ per year among females and $3.06 \mathrm{mmHg}$ per year among males (Model 1, Table 4). This corresponds to an average of 6.31 and $15.5 \mathrm{mmHg}$ over the five-year period among females and males, respectively. The introduction of height into the model reduced the rate of change of SBP with age by $9 \%$ in females and $54 \%$ among males. Systolic blood pressure increased by 0.1 and $0.36 \mathrm{mmHg}$ per centimetre among females and males, respectively (Model 2). Males in this study had an average of $14.5 \mathrm{~cm}$ increase of height over the course of the study. This corresponds to a $5.2 \mathrm{mmHg}$ or $30 \%$ of the expected increase SBP over the five-year period. The $4.2 \mathrm{~cm}$ average increase in height among females corresponds to less than $0.5 \mathrm{mmHg}$ of the expected increase in SBP over the five-year period. 
The introduction of weight in the model reduced the change in SBP per centimetre by $70 \%$ among females and nullified the significant contribution of height to changes of SBP (Table 4, Model 3). On average, males had a $13.6 \mathrm{~kg}$ increase in weight over the course of the study. This corresponds to a $5.0 \mathrm{mmHg}$ or $30 \%$ of the expected increase in SBP. Similarly, the $8.3 \mathrm{~kg}$ average weight increase among females corresponds to a $2.99 \mathrm{mmHg}$ or $45 \%$ of the expected average increase in SBP. Systolic blood pressure increased by approximately 0.9 and $1.0 \mathrm{mmHg}$ per unit increase in BMI among males and females, respectively (Table 1, Model 4). The 2.5 and 1.8 units increase in BMI over the five-year period among males and females, respectively, corresponds to a $2.3(15 \%)$ and $1.8 \mathrm{mmHg}(29 \%)$ of the expected increase in SBP over the duration of the study.

Diastolic blood pressure at age 12 years was slightly higher among females compared to males. Diastolic blood pressure increased on average of 1.06 and $1.92 \mathrm{mmHg}$ per year among females and males, respectively (Table 5, Model 1). This corresponds to an expected increase of 5.3 and $9.6 \mathrm{mmHg}$ over a five-year period among males and females, respectively. The introduction of height in the model decreases the annual DBP rate by $6 \%$ in females and $52 \%$ in males. Height accounted for approximately $34 \%$ of the increase of blood DBP among males and $5 \%$ of the increase among females. As with SBP, introduction of weight into the model rendered the contribution of height insignificant among females and decreased the contribution of height to DBP rate by approximately $50 \%$. The increase in weight over the course of the study corresponds to $34 \%$ and $24 \%$ of the expected rate of change in DBP in females and males, respectively. Similarly, the average increase in BMI corresponds to $19 \%$ and $13 \%$ of the expected rate of change in DBP in females and males, respectively. 
The random intercept (constant) of between 7.54 to 8.24 for females and 5.57 to 9.81 for males suggest that there is unexplained heterogeneity in the level of initial blood pressure among participants. The fact that there was decrease in this intercept as anthropometric variables were added to Model 0 suggests that these variables contributed to the change in blood pressure rate observed during adolescence. A similar pattern is observed for DBP. The relative smaller between-subject random slope (age) suggests that the rate of blood pressure increase is largely independent of age per se although it is strongly dependent of the time varying anthropometric covariates. Finally, the within-subject variance is a reflection of how each participant's BP differs from his/her linear change pattern and indicates that a large part of the variance is due to individual change in blood pressure rate. 


\section{DISCUSSION}

In this study, the anthropometric antecedents of SBP and DBP changes in a cohort of adolescents of African descent followed over a five-year period were evaluated using a multilevel mixed regression approach. The findings suggest that there are gender differences in the contributions of the various anthropometric measures on the rate of blood pressure change. They also suggest that among adolescent females, weight, BMI and adiposity make a much greater contributions to the expected blood pressure increase than height. Among males, the contributions made by height and weight were comparable. This is similar to the finding of other studies using longitudinal data and is consistent with our previous findings from a cross-sectional study on this population (25-27).

The average yearly change in SBP and DBP appears to be higher in the cross-sectional study as compared to this longitudinal study, especially among males. For example, average annual increase in blood pressure was $3.6 \mathrm{mmHg}$ in cross-sectional study and $3.06 \mathrm{mmHg}$ in the longitudinal study. Among females, it was $1.5 \mathrm{mmHg}$ from the cross-sectional study and $1.27 \mathrm{mmHg}$ from the longitudinal study. Incredibly, with the exception of DBP at 18 years among females, there were no significant differences between mean blood pressures generated from cross-sectional and longitudinal data by age among males and females. Thus, there is excellent congruence between estimates resulting from cross-sectional and longitudinal data from this population. This supports the use of cross-sectional data as a basis for determining important blood pressure indices in this population. This is important given the fact that crosssectional data on blood pressure are more easily obtainable than longitudinal data. 
While age seems to have played a minor role in explaining the rate of blood pressure increase in this population, the time-varying anthropometric covariates of BMI, weight, height and per cent body fat were significantly associated with rate of blood pressure increase. It is generally felt that some indices of obesity are more strongly related to blood pressure than others, and therefore their ability to predict cardiovascular diseases. In this study, we evaluated the effect of BMI, weight, height and per cent body fat on blood pressure by entering these individually as covariates in the fixed part of the regression. Most important was the large reduction of the impact of height on change in blood pressure where other anthropometric measures, weight and BMI are added to the model. The result suggests that the contributions of height to changes in SBP and DBP decrease by some $35-50 \%$ with the entry of weight into the models. This suggests that weight may be more closely associated with charges in blood pressure than height per se. In fact, among females the contribution of height to the rate of change in blood pressure was negligible. A glance at the likelihood ratio could suggest that with the exception of per cent body fat, the effect is similar for the other anthropometry and body composition variables in the model. Most noteworthy, was the fact that the maximum likelihood ratios change substantially with adiposity was entered into the model. This suggests that overall the model with adiposity may have best described the rate of changes in blood pressure. With the exception of height, the increase in SBP and DBP per unit increase in anthropometric measure was similar among males and females. The magnitude of variability in SBP with anthropometry is consistent with those reported in other studies on adolescents using a mixed model approach $(15,26)$.

The random intercept and suggests that there is significant intra- individual variation in blood pressure changes in both males and females and that it is important to adjust for these 
when generating blood pressure change estimates. The relative lower level of variance suggested by the random slopes suggest that age per se may not play a major role in determining blood

pressure changes during adolescence. This suggests that there is little intra-individual tracking of blood pressure with age and supports the use of a fixed annual rate of blood pressure increase in this population. This is also supported by the similarity of the average annual increase in blood pressure generated from a cross-sectional study of this population (15).

The main strength of the mixed model approach is that it accounts for intra-individual and inter-individual effects simultaneously, as this has a profound effect on the precision of the intercepts and slopes estimated. The random intercept allows adjustments to the fixed intercepts for the individual differences. Likewise, the random slope influences the slopes of the covariates as well as the fixed intercepts. A major limitation of this study was that no adjustments to the estimates were made for level of maturation and physical activity both of which are known to influence blood pressure levels $(14,26,28)$. This is an important consideration as the level of involvement in physical activity decreases from lower school to upper school where the dictates of the curriculum are focussed on preparation for exit examinations (15).

Anthropometry is an important covariate of blood pressure changes during adolescence. Also, the similarity of blood pressure estimates from longitudinal and cross-sectional data suggest that the latter may provide useful information on age-related blood pressure changes in this population.

\section{ACKNOWLEDGEMENTS}

This study was funded by the Tobago Hypertension Society. We are also grateful for the assistance given to us by school principals as well as nurses from the District Health Services. 


\section{REFERENCES}

1. World Health Organization. Global health risks: mortality and burden of disease attributable to selected major risks. Geneva: World Health Organization; 2009. [Accessed November 11, 2011]. Available from: http://www.who.int/healthinfo/global_burden_disease/GlobalHealthRisks_report_full.pdf

2. Hennis A, Wu SY, Nemesure B, Leske MC, Barbados Eye Studies Group. Hypertension prevalence, control and survivorship in an Afro-Caribbean population. J Hypertens 2002; 20: $2363-9$.

3. Inamo J, Lang T, Atallah A, Inamo A, Larabi L, Chatellier G et al. Prevalence and therapeutic control of hypertension in French Caribbean regions. J Hypertens 2005; 23: $1341-6$.

4. Cruickshank JK, Mbanya JC, Wilks R, Balkau B, Forrester T, Anderson SG et al. Hypertension in four African-origin populations: current 'Rule of Halves', quality of blood pressure control and attributable risk of cardiovascular disease. J Hypertens 2001; 19: $41-6$.

5. Pan American Health Organization, Caribbean Community Secretariat (CARICOM). Report of the Caribbean commission on health and development. Jamaica: Ian Randle Publishers; 2006.

6. Forrester T, Cooper RS, Weatherall D. Emergence of Western diseases in the tropical world: the experience with chronic cardiovascular diseases. Br Med Bull 1998; 54: $463-73$. 
7. Hansen HS, Nielsen JR, Hyldebrandt N, Hobery K. Blood pressure and cardiac structure in children with a prenatal history of hypertension, the Odense school child study. J Hypertens 1992; 10: 677-82.

8. Lever AF, Harrap SB. Essential hypertension: a disorder of growth with origins in childhood? J Hypertens 1992; 10: 101-20.

9. Daniels SR, Loggie JM, Khoury P, Kimball TR. Left ventricular geometry and severe left ventricular hypertrophy in children and adolescents with essential hypertension. Circulation 1998; 97: 1907-11.

10. Chadha SL, Vasan RS, Sarma PS, Shekhawat S, Tandon R, Gopinath N. Age- and heightspecific reference limits of blood pressure of Indian children. Natl Med J India 1999; 12: $150-6$.

11. Juhola J, Magnussen CG, Viikari JSA, Kähönen M, Hutri-Kähönen N, Jula A et al. Tracking of serum lipid levels, blood pressure, and body mass index from childhood to adulthood: the Cardiovascular Risk in Young Finns Study. J Pediatrics 2011; 159: 58490. [Accessed November 11, 2011]. Available from: http://www.sciencedirect.com/science/article/pii/S0022347611002770

12. Toschke AM, Kohl L, Mansmann U, von Kries R. Meta-analysis of blood pressure tracking from childhood to adulthood and implications for the design of intervention trials. Acta Paediatr 2010; 99: 24-9.

13. Rosner B, Prineas RJ, Loggie JM, Daniels SR. Blood pressure nomograms for children and adolescents, by height, sex, and age, in the United States. J Pediatr 1993; 123: $871-86$. 
14. Harding S, Whitrow M, Lenguerrand E, Maynard M, Teyhan A, Cruickshank JK et al. Emergence of ethnic differences in blood pressure in adolescence: the determinants of adolescent social well-being and health study. Hypertension 2010; 55: 1063-9.

15. Nichols S, Cadogan F. Blood pressure and its correlates in Tobagonian adolescents. West Indian Med J 2006; 55: 305-12.

16. Lohman T, Roche A, Mortorell R. Anthropometry standardization reference manual. Champaign, Illinois: Human Kinetics Books; 1988.

17. Lazzer S, Boirie Y, Meyer M, Vermorel M. Evaluation of two foot-to-foot bioelectrical impedance analysers to assess body composition in overweight and obese adolescents. $\mathrm{Br}$ J Nutr 2003; 90: 987-92.

18. Pateyjohns IR, Brinkworth GD, Buckley JD, Noakes M, Clifton PM. Comparison of three bioelectrical impedance methods with DXA in overweight and obese men. Obesity (Silver Spring) 2006; 14: 2064-70.

19. Bousbiat S, Jaffrin MY, Dongmo E. Comparison of body fat-free masses calculated from hand-to-foot and foot-to-foot resistances with DXA measurements. Med Biol Eng Comput 2011; 49: 1329-36.

20. Snijders T, Bosker R. Multilevel analysis. An introduction to basic and advanced multilevel modelling. SAGE Publications; 1999.

21. Scuteri A, Bos AJG, Brant LJ, Talbot L, Lakatta EG, Fleg JL. Hormone replacement therapy and longitudinal changes in blood pressure in postmenopausal women. Ann Intern Med 2001; 135: 229-38.

22. Quene' H, van denBergh H. On multi-level modeling of data from repeated measures designs: a tutorial. Speech Communication 2004; 43: 103-21. 
23. Rabe-Hesketh S, Skrondal A. Multilevel and longitudinal modeling using Stata. College Station, Texas: Stata Press, StataCorp LP; 2005.

24. Blackwell E, Mendes de Leon C, Miller GE. Applying mixed regression models to the analysis of repeated-measures. Psychosom Med 2006; 68: 870-8.

25. Chen X, Wang Y. The influence of sexual maturation on blood pressure and body fatness in African-American adolescent girls and boys. Am J Hum Biol 2009; 21: 105-12.

26. Maximova K, O'Loughlin J, Paradis G, Hanley JA, Lynch J. Changes in anthropometric characteristics and blood pressure during adolescence. Epidemiology 2010; 21: 324-31.

27. Syme C, Abrahamowicz M, Leonard GT, Perron M, Richer L, Veillette S et al. Sex differences in blood pressure and its relationship to body composition and metabolism in adolescence. Arch Pediatr Adolesc Med 2009; 163: 818-25.

28. Sherar LB, Cumming SP, Eisenmann JC, Baxter-Jones AD, Malina RM. Adolescent biological maturity and physical activity: biology meets behaviour. Pediatr Exerc Sci 2010; 22: 332-49. 
Table 1: Physiological characteristics of participants by gender

\begin{tabular}{llll}
\hline Variable & $\begin{array}{l}\text { Females (F) } \\
\text { Mean (SD) }\end{array}$ & $\begin{array}{l}\text { Males }(\mathbf{M}) \\
\text { Mean }(\mathrm{SD})\end{array}$ & $p$-value \\
\hline Systolic Blood Pressure (SBP) (mmHg) & & & \\
11 years $(\mathrm{F}=20, \mathrm{M}=16)$ & $101.4(11.1)$ & $103.0(12.3)$ & 0.690 \\
12 years $(\mathrm{F}=186, \mathrm{M}=154)$ & $102.2(10.9)$ & $100.4(14.1)$ & 0.170 \\
13 years $(\mathrm{F}=308, \mathrm{M}=244)$ & $105.3(12.7)$ & $104.5(12.8)$ & 0.490 \\
14 years $(\mathrm{F}=344, \mathrm{M}=257)$ & $106.3(12.7)$ & $109.2(14.3)$ & 0.008 \\
15 years $(\mathrm{F}=343, \mathrm{M}=278)$ & $107.8(12.3)$ & $112.0(13.2)$ & $<0.001$ \\
16 years $(\mathrm{F}=308, \mathrm{M}=241)$ & $108.4(11.5)$ & $112.5(12.9)$ & $<0.001$ \\
17 years $(\mathrm{F}=164, \mathrm{M}=95)$ & $110.9(13.0)$ & $116.2(12.4)$ & 0.001 \\
18 years $(\mathrm{F}=51, \mathrm{M}=30)$ & $111.6(11.7)$ & $117.4(13.4)$ & 0.060 \\
Diastolic $\mathrm{Blood} \mathrm{Pressure}(\mathrm{DBP})(\mathrm{mmHg})$ & & & \\
11 years $(\mathrm{F}=20, \mathrm{M}=16)$ & $63.9(8.3)$ & $65.0(9.9)$ & 0.720 \\
12 years $(\mathrm{F}=186, \mathrm{M}=154)$ & $64.0(9.4)$ & $63.6(11.1)$ & 0.690 \\
13 years $(\mathrm{F}=308, \mathrm{M}=244)$ & $67.0(10.4)$ & $64.9(10.9)$ & 0.020 \\
14 years $(\mathrm{F}=343, \mathrm{M}=257)$ & $67.9(9.7)$ & $68.6(10.4)$ & 0.430 \\
15 years $(\mathrm{F}=342, \mathrm{M}=277)$ & $69.2(9.6)$ & $69.7(9.5)$ & 0.510 \\
16 years $(\mathrm{F}=315, \mathrm{M}=240)$ & $69.5(8.7)$ & $71.6(9.4)$ & 0.007 \\
17 years $(\mathrm{F}=164, \mathrm{M}=96)$ & $70.4(9.8)$ & $72.2(9.4)$ & 0.09 \\
18 years $(\mathrm{F}=51, \mathrm{M}=30)$ & $70.1(8.1)$ & $73.9(9.9)$ & 0.06 \\
\hline
\end{tabular}


Table 1 (cont'd). Baseline physiological characteristics of participants by gender

\begin{tabular}{lllc}
\hline variable & $\begin{array}{l}\text { Females (F) } \\
\text { Mean (SD) }\end{array}$ & $\begin{array}{l}\text { Males (M) } \\
\text { Mean (SD) }\end{array}$ & $p$-value \\
\hline Pulse Rate $(\mathbf{P R})($ beats/minute) & & & \\
11 years $(\mathrm{F}=20, \mathrm{M}=16)$ & $81.7(11.3)$ & $77.3(11.0)$ & 0.24 \\
12 years $(\mathrm{F}=186, \mathrm{M}=154)$ & $81.8(10.5)$ & $80.2(9.6)$ & 0.13 \\
13 years $(\mathrm{F}=308, \mathrm{M}=244)$ & $80.6(10.2)$ & $78.8(10.4)$ & 0.05 \\
14 years $(\mathrm{F}=344, \mathrm{M}=257)$ & $79.9(9.9)$ & $79.2(9.6)$ & 0.39 \\
15 years $(\mathrm{F}=343, \mathrm{M}=278)$ & $79.6(9.5)$ & $77.7(9.2)$ & 0.01 \\
16 years $(\mathrm{F}=308, \mathrm{M}=241)$ & $80.1(8.8)$ & $76.8(9.3)$ & $<0.001$ \\
17 years $(\mathrm{F}=164, \mathrm{M}=95)$ & $80.8(10.0)$ & $75.2(9.1)$ & $<0.001$ \\
18 years $(\mathrm{F}=51, \mathrm{M}=30)$ & $77.8(8.8)$ & $75.5(7.3)$ & 0.27 \\
& & &
\end{tabular}


Table 2: Anthropometry and body composition of participants by gender

\begin{tabular}{|c|c|c|c|}
\hline Variable & $\begin{array}{l}\text { Females (F) } \\
\text { Mean (SD) }\end{array}$ & $\begin{array}{l}\text { Males (M) } \\
\text { Mean (SD) }\end{array}$ & $p$-value \\
\hline \multicolumn{4}{|l|}{ Weight (kg) } \\
\hline 11 years $(F=20, M=16)$ & $44.9(9.6)$ & $47.3(15.1)$ & 0.590 \\
\hline 12 years $(F=186, M=154)$ & $49.0(10.6)$ & $46.2(11.9)$ & 0.020 \\
\hline 13 years $(\mathrm{F}=308, \mathrm{M}=254)$ & $53.9(12.6)$ & $51.7(13.0)$ & 0.030 \\
\hline 14 years $(\mathrm{F}=329, \mathrm{M}=258)$ & $56.1(13.0)$ & $57.9(12.3)$ & 0.080 \\
\hline 15 years $(\mathrm{F}=345, \mathrm{M}=275)$ & $57.9(12.7)$ & $62.9(13.4)$ & $<0.001$ \\
\hline 16 years $(\mathrm{F}=314, \mathrm{M}=234)$ & $59.1(13.1)$ & $66.2(13.4)$ & $<0.001$ \\
\hline 17 years $(F=161, M=95)$ & $61.5(14.8)$ & $68.3(11.3)$ & $<0.001$ \\
\hline 18 years $(\mathrm{F}=51, \mathrm{M}=30)$ & $62.4(12.3)$ & $66.7(9.8)$ & 0.1 \\
\hline \multicolumn{4}{|l|}{ Height (cm) } \\
\hline 11 years $(F=20, M=16)$ & $156.5(6.7)$ & $154.8(10.3)$ & 0.550 \\
\hline 12 years $(\mathrm{F}=186, \mathrm{M}=175)$ & $159.1(7.7)$ & $161.3(9.2)$ & 0.016 \\
\hline 13 years $(\mathrm{F}=307, \mathrm{M}=244)$ & $161.9(7.3)$ & $162.2(9.6)$ & 0.66 \\
\hline 14 years $(\mathrm{F}=344, \mathrm{M}=259)$ & $163.5(7.2)$ & $169.1(8.9)$ & $<0.001$ \\
\hline 15 years $(\mathrm{F}=345, \mathrm{M}=276)$ & $164.5(6.7)$ & $173.4(7.7)$ & $<0.001$ \\
\hline 16 years $(\mathrm{F}=316, \mathrm{M}=239)$ & $165.3(7.5)$ & $176.4(7.3)$ & $<0.001$ \\
\hline 17 years $(\mathrm{F}=162, \mathrm{M}=96)$ & $166.6(6.6)$ & $176.6(7.3)$ & $<0.001$ \\
\hline 18 years $(\mathrm{F}=51, \mathrm{M}=30)$ & $167.2(6.2)$ & $177.0(6.2)$ & $<0.001$ \\
\hline
\end{tabular}


Table 2 (continued). Anthropometry and body composition of participants by gender

\begin{tabular}{|c|c|c|c|}
\hline Variable & $\begin{array}{l}\text { Females (F) } \\
\text { Mean (SD) }\end{array}$ & $\begin{array}{l}\text { Males (M) } \\
\text { Mean (SD) }\end{array}$ & $p$-value \\
\hline \multicolumn{4}{|l|}{ BMI $\left(\mathrm{kg} / \mathrm{m}^{2}\right)$} \\
\hline 11 years $(\mathrm{F}=20, \mathrm{M}=16)$ & $18.6(3.1)$ & $19.3(4.2)$ & 0.53 \\
\hline 12 years $(\mathrm{F}=186, \mathrm{M}=154)$ & $18.8(3.6)$ & $18.8(3.6)$ & 0.17 \\
\hline 13 years $(\mathrm{F}=308, \mathrm{M}=249)$ & $20.3(3.8)$ & $19.5(4.3)$ & 0.02 \\
\hline 14 years $(\mathrm{F}=344, \mathrm{M}=260)$ & $20.9(3.8)$ & $20.1(3.7)$ & 0.02 \\
\hline 15 years $(\mathrm{F}=345, \mathrm{M}=275)$ & $21.4(4.5)$ & $20.9(4.1)$ & 0.16 \\
\hline 16 years $(\mathrm{F}=315, \mathrm{M}=238)$ & $21.6(4.9)$ & $21.3(4.1)$ & 0.29 \\
\hline 17 years $(\mathrm{F}=162, \mathrm{M}=88)$ & $22.2(5.3)$ & $21.9(3.9)$ & 0.76 \\
\hline 18 years $(\mathrm{F}=51, \mathrm{M}=30)$ & $22.4(4.4)$ & $21.1(2.7)$ & 0.19 \\
\hline \multicolumn{4}{|l|}{ Adiposity (\%) } \\
\hline 12 years $(\mathrm{F}=186, \mathrm{M}=154)$ & $28.5(7.2)$ & $18.6(6.3)$ & $<0.01$ \\
\hline 13 years $(\mathrm{F}=308, \mathrm{M}=249)$ & $27.5(7.5)$ & $15.7(7.1)$ & $<0.01$ \\
\hline 14 years $(\mathrm{F}=344, \mathrm{M}=260)$ & $28.0(7.5)$ & $14.6(9.2)$ & $<0.01$ \\
\hline 15 years $(\mathrm{F}=345, \mathrm{M}=275)$ & $29.2(7.7)$ & $14.5(8.0)$ & $<0.01$ \\
\hline 16 years $(\mathrm{F}=315, \mathrm{M}=238)$ & $29.4(8.2)$ & $14.4(7.0)$ & $<0.01$ \\
\hline 17 years $(\mathrm{F}=162, \mathrm{M}=88)$ & $29.9(8.4)$ & $14.3(8.3)$ & $<0.01$ \\
\hline 18 years $(\mathrm{F}=51, \mathrm{M}=30)$ & $31.6(7.9)$ & $15.4(5.3)$ & $<0.01$ \\
\hline
\end{tabular}


Table 3: Age and sex-specific tracking correlation coefficients for systolic and diastolic blood pressuire at one- and three-year intervals

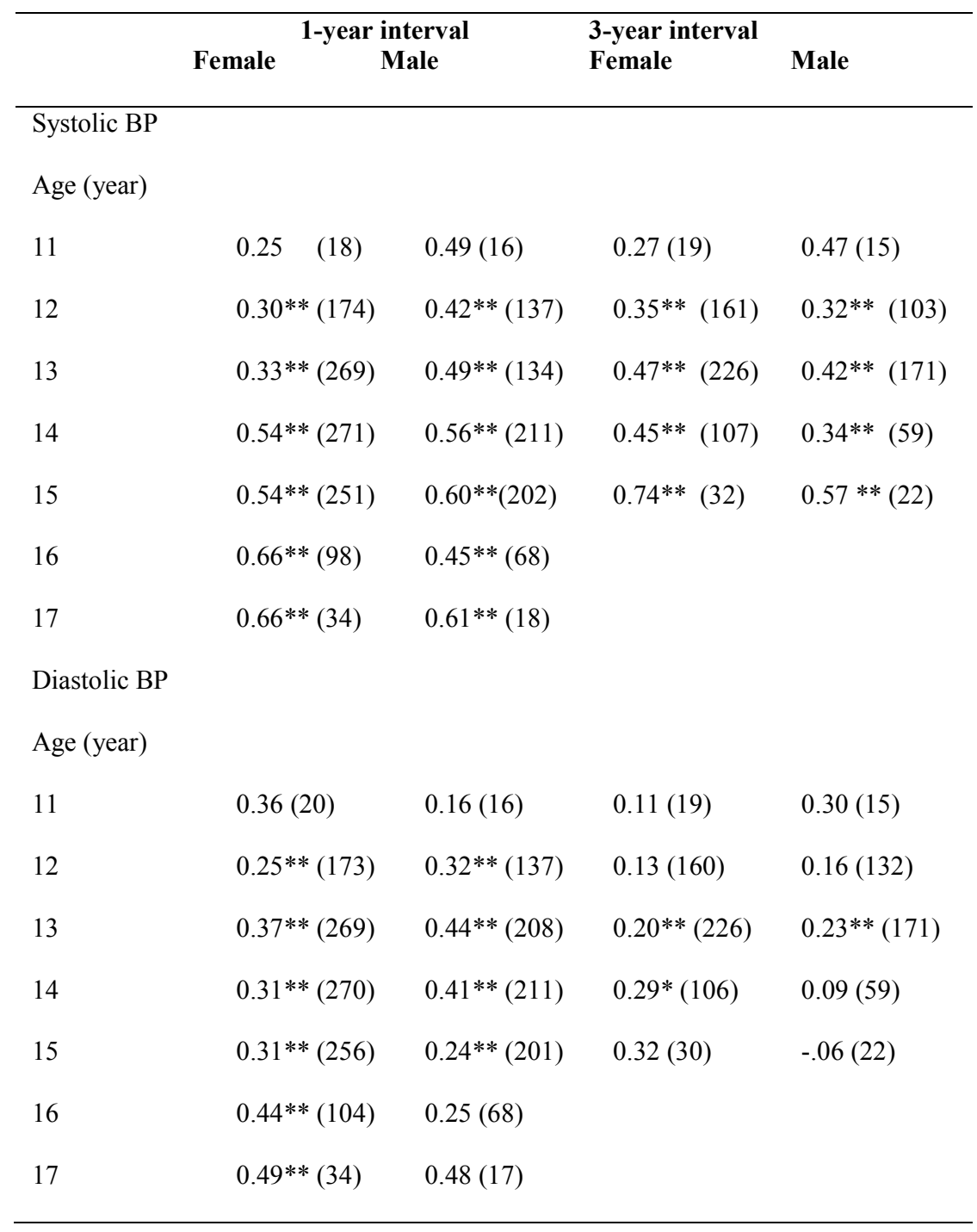


Females

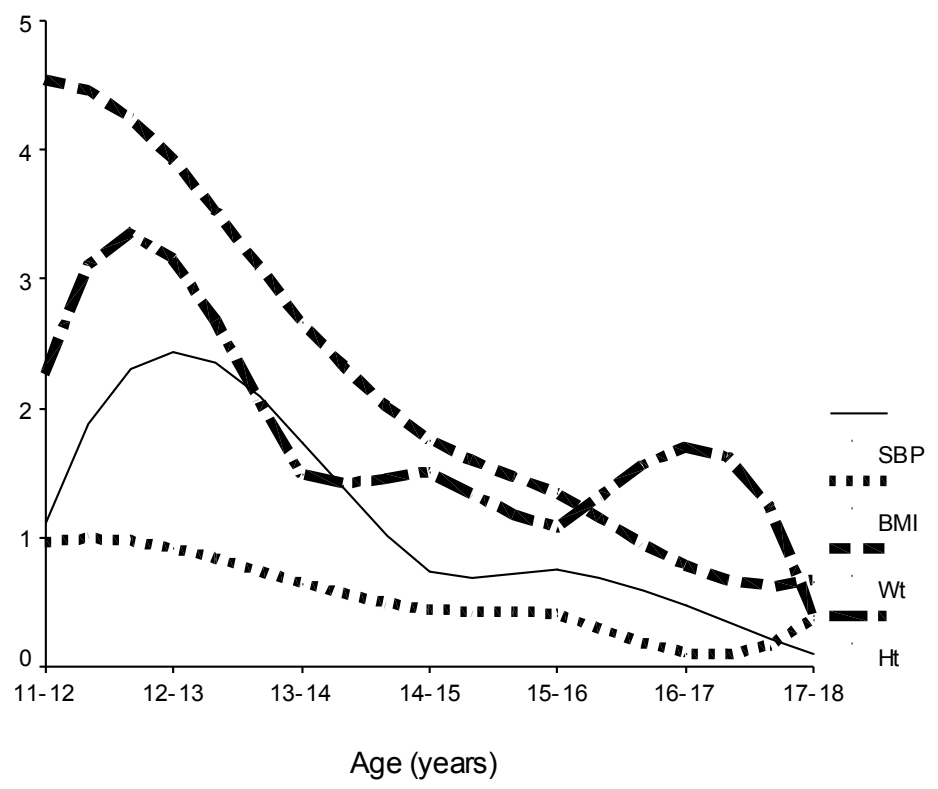

Males

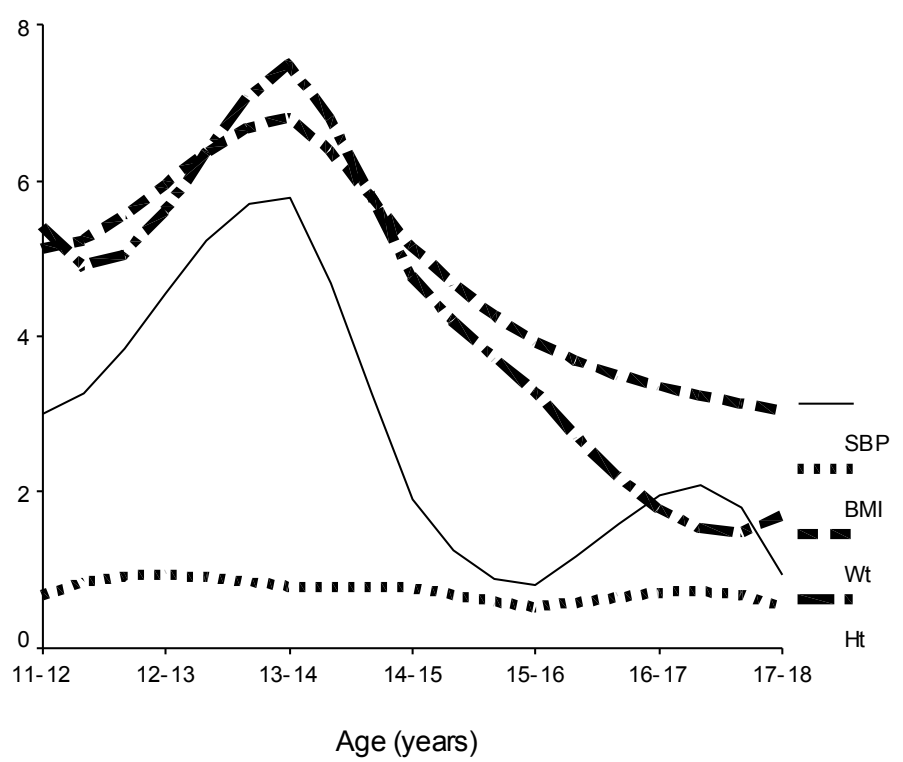

Fig. 1: Annual rates of changes in systolic blood pressure, BMI, weight and height among participants.

$\mathrm{SBP}$ - systolic blood pressure, BMI - body mass index, $\mathrm{Wt}$ - weight, $\mathrm{Ht}$ - height 
Females

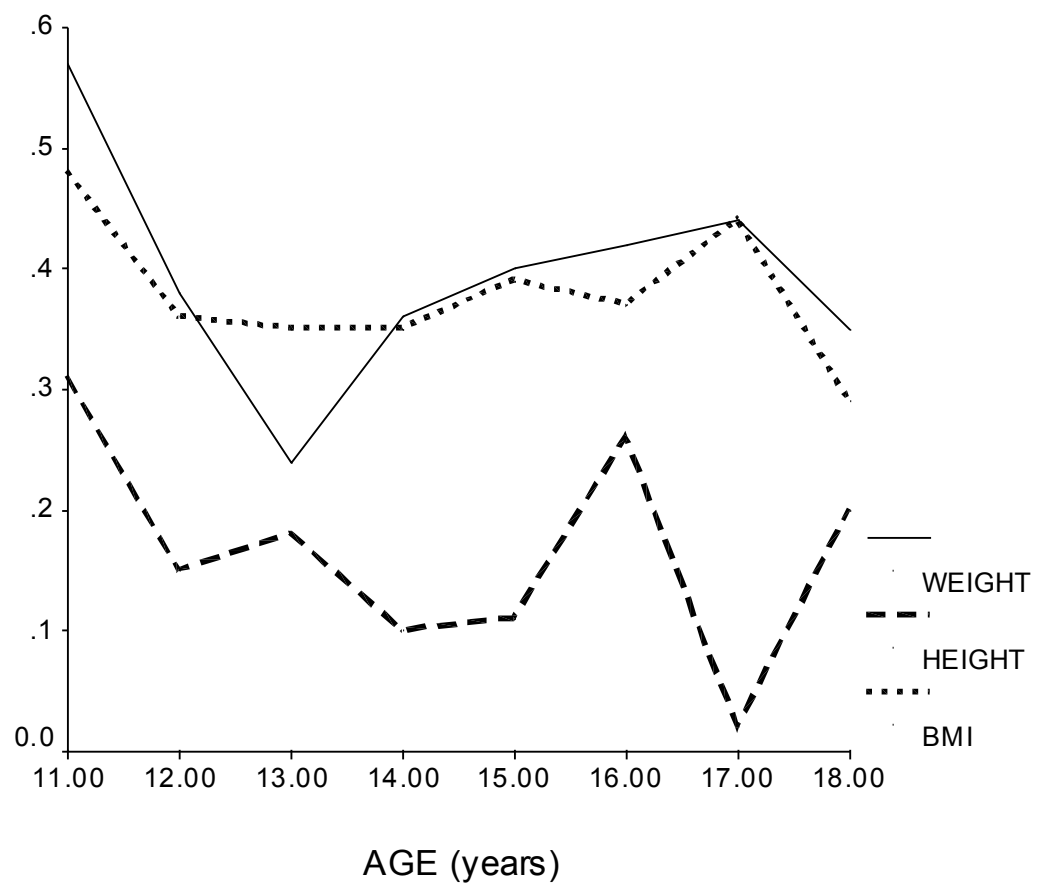

Males

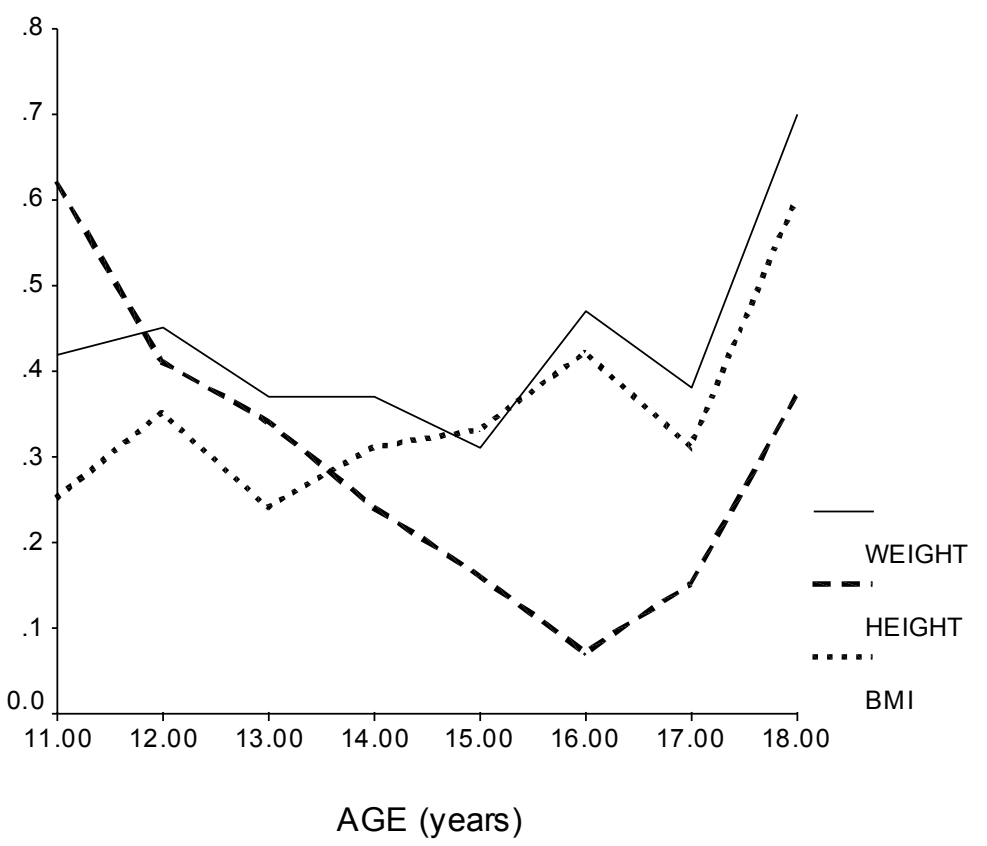

Fig. 2: Correlation of annual body weight, height and body mass index (BMI) with systolic blood pressure among participants. 


\section{Females}

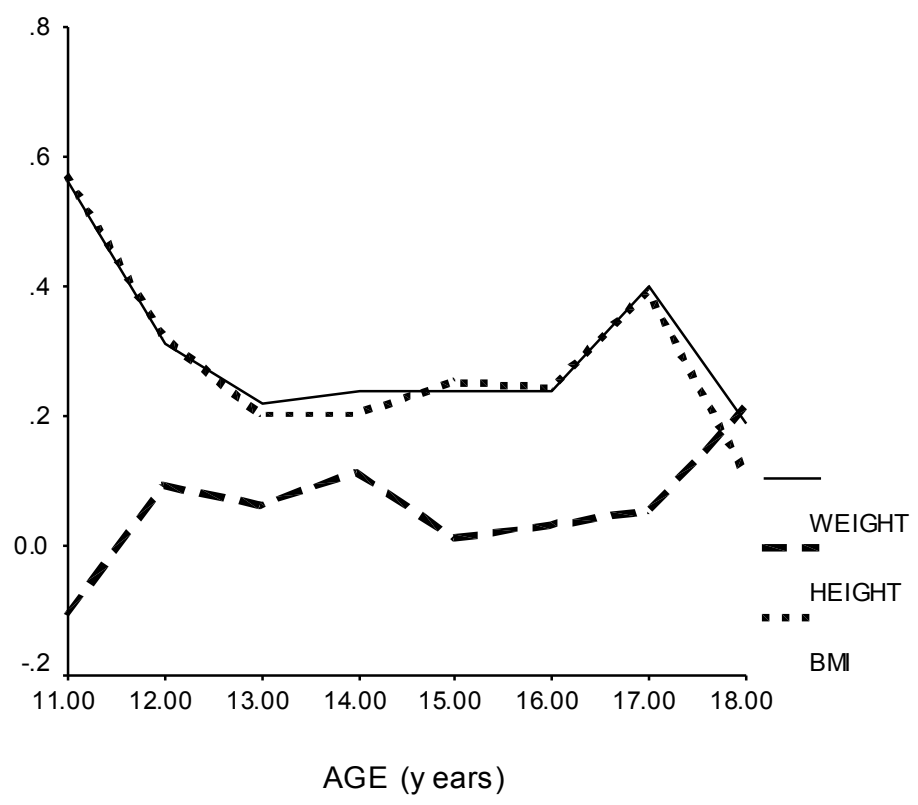

Males

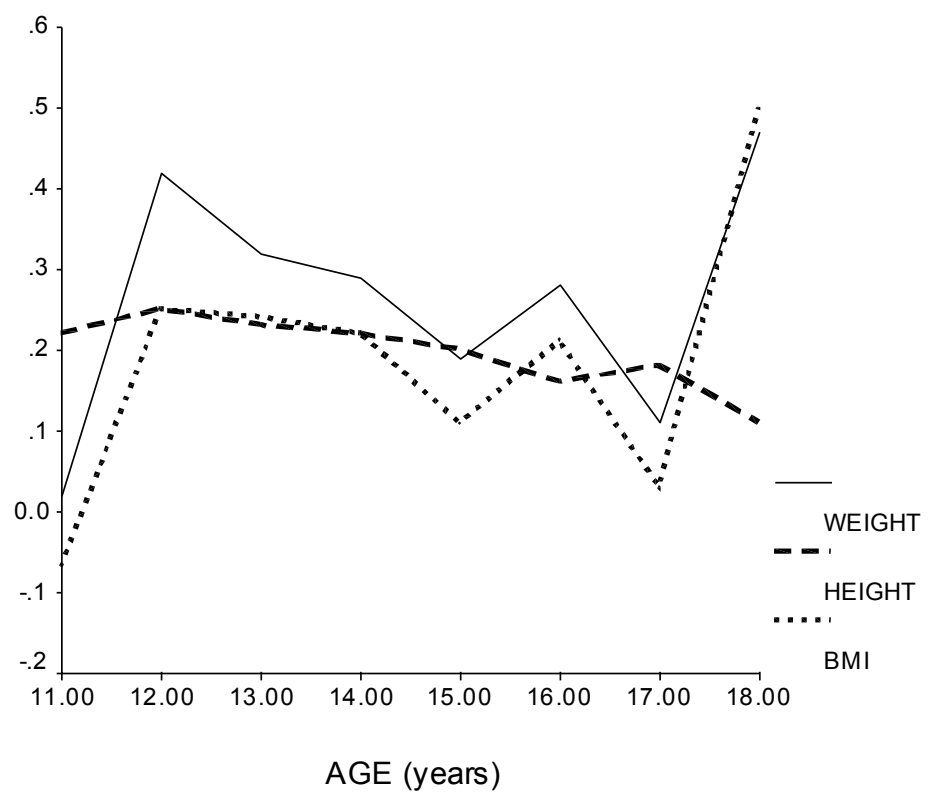

Fig. 3: Correlation of annual body weight, height and body mass index (BMI) with diastolic blood pressure among participants. 
Females

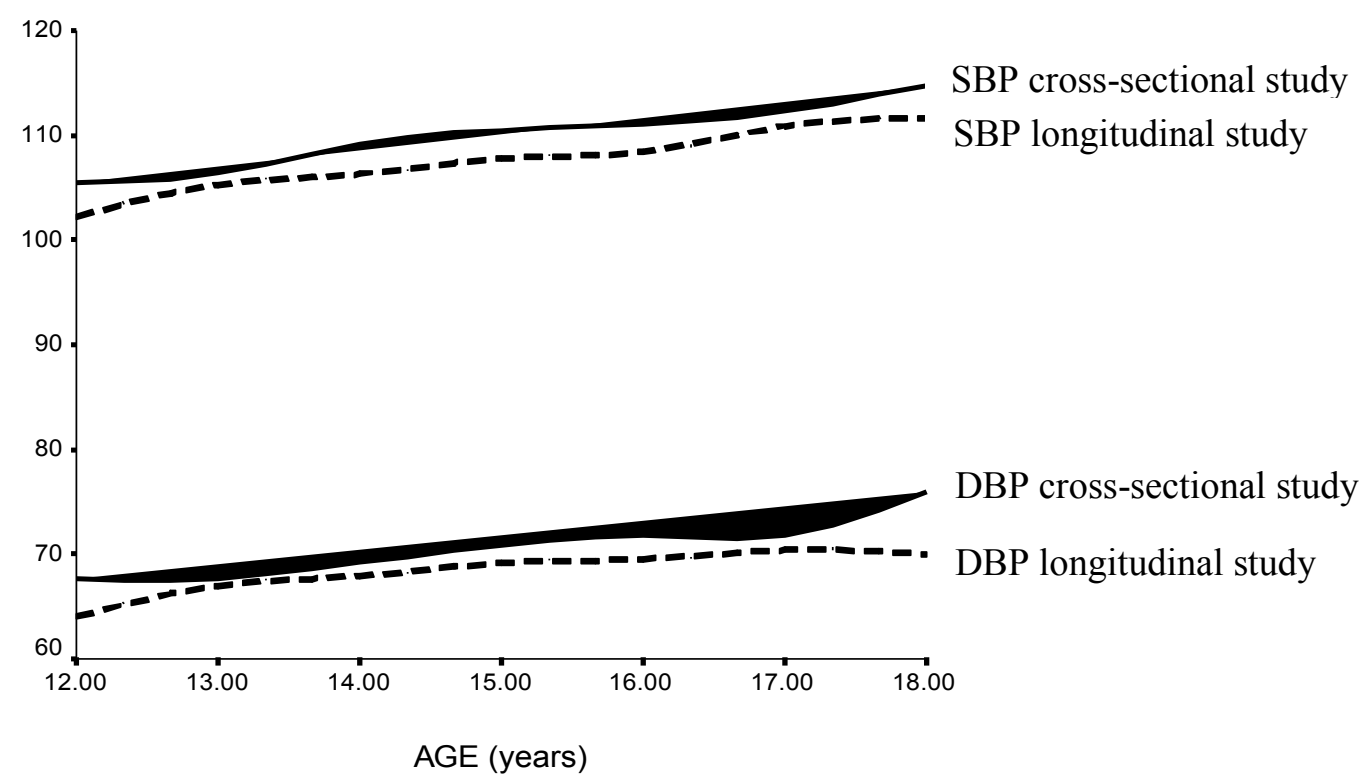

Males

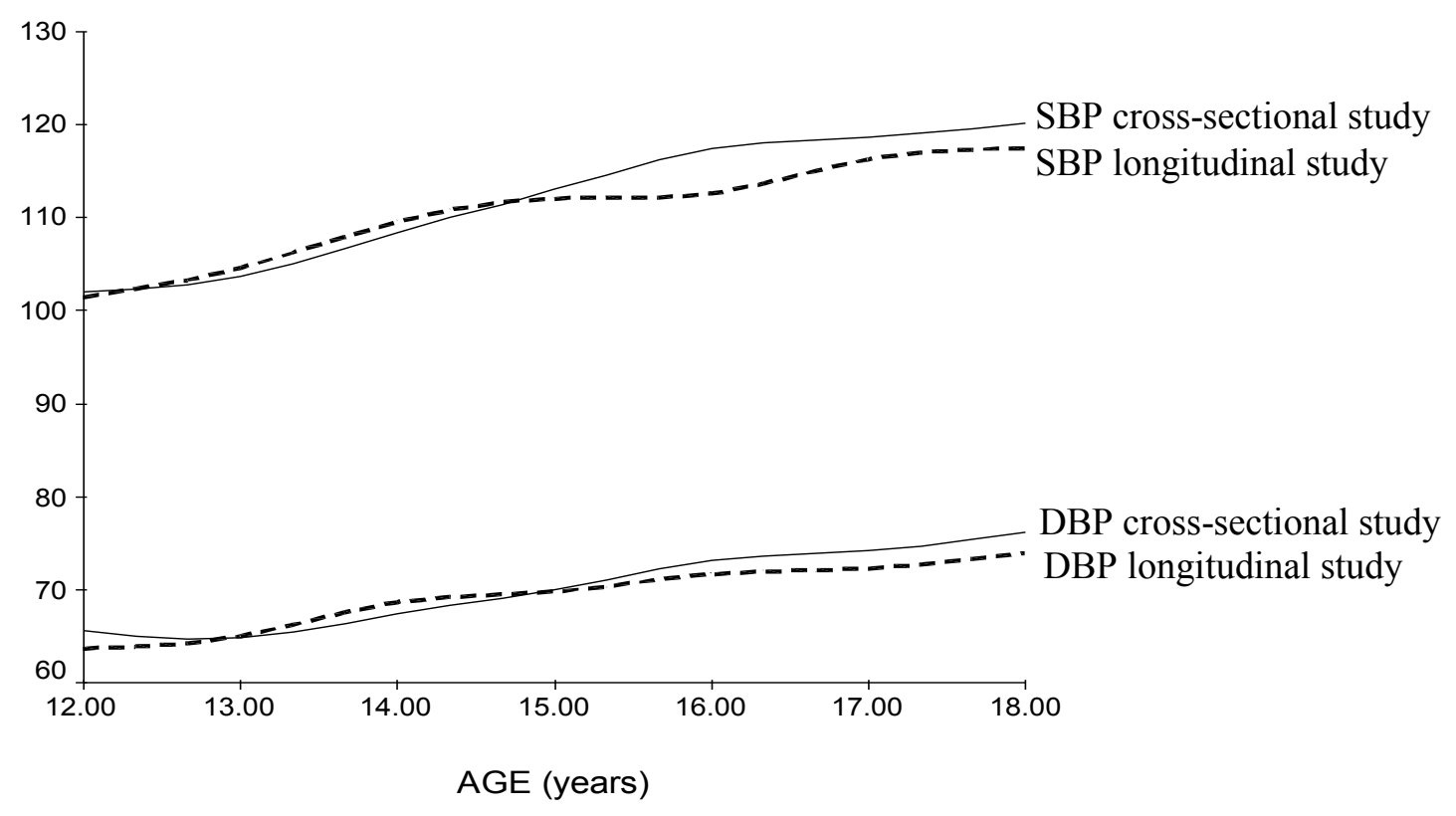

Fig. 4: Comparison of blood pressure changes with age from cross-sectional and longitudinal data by gender 
Table 4: Modelling the effect of age and anthropometry on the rate of systolic blood pressure change among participants

\begin{tabular}{llllll}
\hline Variable & Model 1 & Model 2 & Model 3 & Model 4 & Model 5
\end{tabular}

Fixed Effects

Constant

\begin{tabular}{|c|c|c|c|c|c|}
\hline Females & $104.0(0.60)$ & $88.5(8.3)$ & $96.8(7.7)$ & $55.2(7.9)$ & $66.3(9.1)$ \\
\hline Males & $101.4(0.86)$ & $48.0(7.8)$ & $67.4(7.96)$ & $27.5(7.8)$ & $29.8(9.0)$ \\
\hline \multicolumn{6}{|l|}{ Age } \\
\hline Females & $1.27(0.15)$ & $1.16(0.16)$ & $0.66(0.16)$ & $0.64(0.16)$ & $1.05(0.18)$ \\
\hline Males & $3.09(0.22)$ & $1.41(0.37)$ & $0.83(0.31)$ & $0.82(0.31)$ & $1.4(0.36)$ \\
\hline \multicolumn{6}{|l|}{ Height } \\
\hline Females & & $0.10(0.05)$ & $-0.07(0.04)$ & $0.19(0.05)$ & $0.17(0.05)$ \\
\hline Males & & $0.36(0.05)$ & $0.11(0.05)$ & $0.35(0.05)$ & $0.42(0.05)$ \\
\hline \multicolumn{6}{|l|}{ Weight } \\
\hline Females & & & $0.35(0.02)$ & & \\
\hline Males & & & $0.36(0.04)$ & & \\
\hline
\end{tabular}

\section{BMI}

$\begin{array}{ll}\text { Females } & 0.93(0.08)\end{array}$

$\begin{array}{ll}\text { Males } & 1.01(0.11)\end{array}$

Per cent Body Fat

Females

$0.32(0.06)$

Males

$0.31(0.06)$ 


\section{Random Effects}

\begin{tabular}{|c|c|c|c|c|c|}
\hline Between Subjects & $7.30(0.59)$ & & & & \\
\hline Constant & $9.81(0.77)$ & & & & \\
\hline Females & & $7.08(0.60)$ & $8.23(0.80)$ & $8.24(0.81)$ & $7.54(1.05)$ \\
\hline Males & $0.35(0.27)$ & $8.5(.80)$ & $5.68(0.57)$ & $5.57(0.57)$ & $6.17(0.63)$ \\
\hline Age & $1.92(0.33)$ & & & & \\
\hline Females & & $0.40(0.18)$ & $0.42(0.17)$ & $0.45(0.17)$ & $0.32(0.19)$ \\
\hline Males & $8.9(0.17)$ & $1.76(0.34)$ & $1.67(0.35)$ & $1.71(0.34)$ & $1.38(0.30)$ \\
\hline Within Individual & $9.37(0.33)$ & & & & \\
\hline Females & & $8.3(0.91)$ & $8.9(0.75)$ & $8.9(0.77)$ & $8.68(0.20)$ \\
\hline Males & 72.3 & $9.85(0.25)$ & $9.27(0.24)$ & $9.28(0.25)$ & $9.62(0.72)$ \\
\hline Wald Test & 202 & & & & \\
\hline Females & -6668 & 75 & 223 & 226 & 113 \\
\hline Males & -6550 & 264 & 360 & 360 & 254 \\
\hline Likelihood & $5454(5100)$ & & & & \\
\hline Female & & -6543 & -6481 & -6480 & -5073 \\
\hline Male & & -5076 & -5023 & -5023 & -3745 \\
\hline
\end{tabular}


Table 5: Modelling the effect of age and anthropometry on the rate of diastolic blood pressure change among participants

\begin{tabular}{llllll}
\hline Variable & Model 1 & Model 2 & Model 3 & Model 4 & Model 5
\end{tabular}

Fixed Effects

Constant

$\begin{array}{lllllr}\text { Females } & 65.6(0.50) & 53.3(0.93) & 60.3(1.26) & 37.40(1.54) & 28.9(1.57) \\ \text { Males } & 63.5(0.61) & 27.58(5.89) & 37.76(5.98) & 18.13(5.97) & 19.7(7.10) \\ \text { Age } & & & & & \\ \text { Females } & 1.06(0.13) & 1.0(0.14) & 0.69(0.14) & 0.68(0.14) & 0.86(0.17) \\ \text { Males } & 1.92(0.16) & 0.93(0.25) & 0.65(0.23) & 0.63(0.23) & 0.66(0.28)\end{array}$

Height

$\begin{array}{lllll}\text { Females } & 0.05(0.04) & -0.06(0.04) & 0.09(0.04) & 0.14(0.04)\end{array}$

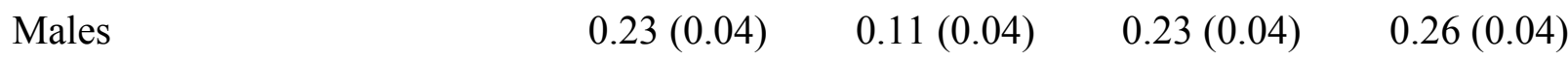

Weight

$\begin{array}{ll}\text { Females } & 0.21(0.02)\end{array}$

$\begin{array}{ll}\text { Males } & 0.17(0.03)\end{array}$

\section{Body Mass Index}

Females

$0.56(0.06)$

Males

$0.49(0.08)$

\section{Per cent Body Fat}

Females

$0.19(0.09)$

Males

$0.19(0.05)$ 


\section{Random Effects}

Between Subjects

\section{Constant}

Females

$5.78(0.65) \quad 5.69(0.66)$

$5.14(0.67)$

$5.09(0.67)$

$5.00(0.78)$

Males

$6.56(0.69) \quad 6.00(0.69)$

$5.64(0.70)$

$5.60(0.70)$

$5.20(0.41)$

Age

Females

$0.84(0.34) \quad 0.85(0.34)$

$0.78(0.35)$

$0.78(0.35)$

$0.94(0.36)$

Males

$0.69(0.47) \quad 0.56(0.56)$

$0.56(0.56)$

$0.56(0.55) \quad 0.0001(0.0001)$

\section{Within Individual}

Females

$8.02(0.18)$

$8.03(0.18)$

$8.00(0.18)$

$8.00(0.18)$

8.02(0.18)

Males

$8.30(0.20) \quad 8.26(0.20)$

$8.22(0.20)$

$8.22(0.20)$

$8.27(0.22)$

Wald Test

Females

$62.1 * * *$

$63.5 * * *$

$152.8 * * *$

$158.3 * * *$

$78.2 * * *$

Males

$114.0 * * *$

$184.8 * * *$

$228 * * *$

$228.77 * * *$

$136^{* * *}$

Likelihood

Female

$-6349$

$-6340$

$-6300$

$-6297$

$-4949$

Male

$-4831$

$-4811$

$-4780$

$-4779$

$-3570$ 